\title{
Profit Efficiency of Smallholder Pig Farmers in Tharaka-Nithi County, Kenya
}

\author{
Pauline Micheni $^{1^{*}} \quad$ Newton Nyairo ${ }^{2} \quad$ Nigat Bekele $^{3} \quad$ Geoffrey Kosgei ${ }^{1}$ \\ 1.Department of Agricultural Economics, Agribusiness Management and Agricultural Education and Extension, \\ Chuka University, PO box 109-60400, Chuka, Kenya \\ 2.Department of Agricultural Sciences Education and communication, Purdue University, 915 West State street, \\ West Lafayette, IN 47907-2054176 \\ 3.Department of Agribusiness Management and Trade, Kenyatta University, PO box 176 43844-00100, Nairobi, \\ Kenya
}

\begin{abstract}
The aim of this study was to determine the profit efficiency of the smallholder pig farmers in Tharaka-Nithi County, Kenya. The study carried out a census of 80 smallholder pig farmers. The data was collected with the help of semistructured interview schedule. The study found out that five farms had profit efficiency score of 1 thus they were efficient while the rest were inefficient. The most inefficient farm had inefficiency level of 0.005 , thus had to reduce input costs by $99.5 \%$ in order to acquire its target value. The mean profit efficiency results were $40 \%$ implying that efficiency level could be increased by $60 \%$ through reducing the excess inputs used and better use of available resources. This would be acquired if good management practices and marketing channels are adopted. The average input slack value of 1208 which means farmers had a chance of reducing their input costs by this amount per year without compromising their output. Benchmarks can be established from the best practices farms which can be used as a package for enhancing and stabilizing profit efficiencies of smallholder pig farmers which in turn could help improve the Kenya economy. The study also recommends policy interventions pertaining to pig enterprise inputs, marketing issues and financial products in order to improve pig farmers' livelihoods.
\end{abstract}

Keywords: Small Holder Farmers, Profit Efficiency, Data Envelopment Analysis, Decision Making Unit

DOI: $10.7176 / \mathrm{JESD} / 11-10-16$

Publication date:May $31^{\text {st }} 2020$

\section{Introduction}

The pig industry in Tharaka Nithi County, Kenya is mainly dominated by smallholder farmers (SHFs) like other agricultural sub sectors. Several factors such as suitable climate, less land required, quick returns on investments due to large litter size and faster maturity rate contribute to success of pig production by smallholders. However, low productivity among SHFs remains a major obstacle to food security. Improved farming methods, quality inputs, reliable and efficient markets, credit access and favorable policies have been identified as crucial to improve productivity. Unfortunately, the SHFs are not well organized and therefore do not command a voice that can facilitate their access to appropriate services with a unified voice. In addition, due to poor husbandry practices, the farmers register low yields which generate very low returns. SHFs lack a business orientation, meaning they do not operate their farming enterprise as a business (Mutua et al, 2010).

Pig farming play an important role in risk diversification and livelihood security of smallholder and households as they are important assets useful in generating income for purchase of farm inputs, school fees payment and covering emergency cash needs (Mutua et al, 2010). With the poverty level of $65 \%$ in the county KNBS (2009) the populace needs to undertake farm enterprises which will offer quick returns on investments like pig farming. The small-scale pig farming enterprise has been found to be very profitable if good husbandry practices and management skills are applied (FAO, 2012). Improving the productivity of smallholder pig farmers, therefore, has a huge potential to meet these multi-functions of the pigs.

However, smallholder pig farmers in Tharaka-Nithi County obtain varying and dismal profits from their enterprise. Pig sub-sector has a seemingly greater potential if the enterprise is carried as a business. Good management skills and efficient institutional arrangements will increase pig production, increase income and eventually increase profit levels of farmers. Dismal profits can be attributed to a number of productivity and market related constraints ranging from diseases, poor nutrition and poorly organized markets due to personal negotiations and absence of contracts (Levy et al, 2014).

Development of the pig value chain is important as it has an effect on the farmers' profits. This is because all the actors in the chain will actively seek to support each other so that they can increase their efficiency and competitiveness (KIT et al, 2006). The pig sub sector in the county is largely informal with poorly organized markets, limited to technology, information and services. Additionally, lack of feed quality control measures, disease risks that wipe out pig herds during outbreak periods lead to stunted growth which reduce market value. Exchange of goods and information in the produce market is also affected by lack of farmer organizations in the pig sector. This will lead to high transactions costs due to low binding relationships between smallholder farmers 
and traders (Key et al, 2000). Therefore, to minimize these high transaction costs, smallholder farmers need to establish efficient institutional arrangements.

Varying and dismal profits of smallholder pig farmers are caused by therefore productivity and market related factors (Mutua et al, 2010; Kagira and Maingi, 2010). Research on whether management factors (farm and farmer characteristics) as well as institutional arrangements from transaction cost perspective influence varying and dismal profits has not been adequately researched. Of all the previous studies done on analysis of profit efficiency in smallholder pig farmers (Kadurumba, 2014; Costales, 2006), none focused on the application of Data Envelopment Analysis (DEA)

\section{Methodology}

\subsection{The Study Area}

Tharaka-Nithi County is one of the 47 counties that were formed after the dispensation of the new constitution of Kenya 2010. It's one of the counties that form part of the Eastern region. It borders the counties of Embu to the south and south-west, Meru to the north and north-east, Kirinyaga and Nyeri to the west, and Kitui to the east and south east. The county lies between latitudes 00o 07' and 00026' South and between longitudes 370 19' and 370 46' East. The total area of the county is $2,662.1 \mathrm{~km} 2$ (GOK, 2013).

The rainfall ranges between 1000 to $1400 \mathrm{~mm}$ per annum; with temperatures ranging from a minimum of $11 \mathrm{oC}$ to a maximum of $25.9 \mathrm{o}$ C. the rainfall pattern is bimodal: the long rains fall between March and June, while the short rains fall between October and December (Jaetzold and Schimidt, 1983).

The agro-ecology of this area is influenced by high altitude of $1500 \mathrm{~m}$ above sea level, thus part of the county is a highland and thus a conducive environment to rear pigs. Pigs especially large white are affected by heat stress therefore the researcher was motivated to select this area. The area is characterized by complex farming systems with annual and perennial crops both for cash and food, as well as livestock. The major cash enterprises are tea and dairy. Farmers rely mainly on rain-fed agriculture and the food crops they farm might be affected by uncertainty of weather conditions. The smallholder pig farmers in the selected County differ in terms of management factors and institutional arrangements which emanate from farm and farmer characteristics as well as the marketing channels adopted.

\subsection{Sample size}

In this study, the following formula was used to calculate the sample size (Kothari, 2005).

$\mathrm{n}=\frac{Z^{2} \mathrm{Pq}}{\mathrm{e}^{2}}$

Where:

$\mathrm{n}=$ the desired sample size

$\mathrm{q}=1-\mathrm{p} \quad(1-0.05)$

$\mathrm{Z}=$ the standard normal deviation at confidence level (95\%) which is 1.96

$\mathrm{e}=$ Acceptable error (precision)

$\mathrm{P}=$ the proportion in the target population estimated to have characteristics being measured which will be 0.05 of the total population. Total population of Maara constituency is 107125 , with approximately 5000 smallholder pig farmers. Therefore 0.05 of this population is 5000 .

Thus, sample size $=\frac{(1.96)^{2}(0.05)(0.95)}{0.05^{2}}=$

$$
\mathrm{n}=73
$$

A sample size of 80 farmers was selected from the population of the Smallholder pig farmers in the county. This allowed the researcher to achieve the required sample size in the situation of non-response and spoilt questionnaires.

\subsection{Empirical Framework}

Profit efficiency of the smallholder pig farms in the constituency were established by use of the Data Envelopment Analysis (DEA) since it does not assume a functional form. Data envelopment analysis compares the levels of outputs and inputs for a given decision making unit (DMU) against all other DMU in the data set to determine which DMU are producing at efficient levels relative to the entire group (Coelli, 1996).

The data envelopment analysis (DEA) is a non-parametric mathematical programming approach to frontier estimation (Coelli, 1995). According to Charnes et al (1994) it can be used in analyzing efficiency in production and profitability.

The DEA method simultaneously compares and ranks similar peer groups with respect to each Decision Making Unit's (DMU) relative efficiency (Cooper et al., 2006). The idea is that by determining which DMUs are inefficient (with respect to other DMUs), it can also be determined how they may improve their efficiency i.e., what inputs and by how much each needs to be changed (reduced) to produce the required output to move up in the rank.

DMU refer to any entity that is to be evaluated in terms of its abilities to convert inputs into outputs. The 
efficiency of a decision-making unit (DMU) is measured relative to the efficiency of all the other DMUs subject to the restriction that all DMUs are on or below the frontier. Cooper et al (2006) concludes that a farm can be rated as fully efficient $(100 \%)$ on the basis of available evidence if and only if the performances of other DMUs does not show that some of its inputs or outputs can be improved without worsening some of its other inputs or outputs.

The model included a number of inputs that were considered critical in pig production. The efficient scores provided benchmarks to be used for comparison in the industry. Farmers' net revenue was considered as the farm output while the production and marketing costs were considered as the critical inputs to determine profit efficiency of a farm. The output (net revenue) was got from the total revenue minus total cost. Total revenue was the price of pork multiplied by the quantity of pork while total costs were got from the input costs. The input costs included were feed costs, labor wages, veterinary and drug costs, contacting/search costs and contracting costs which were solved to come up with profit efficiency rankings that showed the best performing farmers. $\mathrm{NR}=P_{q}(\mathrm{Q})-\mathrm{x}($ Feed cost, veterinary and drugs expenses, labor wages, contacting and contracting costs).

Where NR is the Net Revenue of the farmer $\mathrm{p}_{\mathrm{q}}$ is pork price and $\mathrm{Q}$ is the quantity of pork per $\mathrm{kg}$ $\mathrm{x}$ is a vector of inputs.

This work utilized the constant return to scale (CRS) proposed by Charnes et al (1994) which allows one to represent technology using a unit isoquant. When we have constant returns to scale also, the input and output oriented measures of technical efficiency will be equal. Input orientation refers to how to proportionally reduce the quantity of inputs without changing the output produced.

The quantity of input that is in excess and requires reduction and still obtains the same level of output as before is referred to as the input slack or input excess. The model is developed with the following assumptions; we have an enterprise with $\mathrm{K}$ inputs and $\mathrm{M}$ outputs and on each of the $\mathrm{N}$ farms. This is represented by $\mathrm{x}_{i}$ and $\mathrm{y}_{i}$ respectively. We therefore have a $\mathrm{K} x \mathrm{~N}$, input matrix, $\mathrm{X}$, and the $\mathrm{Mx} \mathrm{N}$, output matrix, $\mathrm{Y}$, represent the data of all $\mathrm{N}$ farms. DEA develops a non-parametric envelopment frontier over the data points such that all observed points lie on or below the production frontier.

\subsection{Model Specification}

Data Envelopment Analysis (DEA) method was used to achieve the results of the study. In this case then DEA tries to find an optimal ratio of all the outputs over the inputs and thus the optimal combinations of inputs that will result to optimal profits were determined.

$\pi^{j}(P q, X c)=\max \left(\sum_{n=1}^{N} \mathrm{P}_{\mathrm{q}} \mathrm{Q}-\sum_{i=1}^{N} \mathrm{X}_{\mathrm{C}}\right) \mathrm{j}=1, \ldots ., \mathrm{K}$

S.t

$\sum_{k=1}^{K} Z^{k} Q_{n}^{k} \geq Q_{n} \mathrm{n}=1 \ldots \mathrm{N}$ (Outputs)

$\sum_{k=1}^{K} Z^{K} X_{i}^{K} \leq X_{i} \quad \mathrm{i}=1, \ldots, \mathrm{I}$ (Variable costs)

$\sum_{k=1}^{K} Z^{k} x_{f i}^{k} \leq x_{f i}^{k} \quad \mathrm{f}_{\mathrm{i}}=1+1, \ldots, \mathrm{m}$ (fixed inputs)

$\sum_{k=1}^{K} Z^{K}=1$

(Whittaker et al, 1995; Jacobs, 2000)

Where;

$\pi^{\mathrm{j}}$ is total profit of the $\mathrm{j}^{\text {th }}$ farmer

$\mathrm{P}_{\mathrm{q}}$ is the output price

$\mathrm{Q}$ is the output quantity

$\mathrm{X}_{\mathrm{ci}}$ is the $\mathrm{i}^{\text {th }}$ variable input expenditure

$\mathrm{X}_{\mathrm{fi}}$ is the $\mathrm{i}^{\mathrm{th}}$ fixed input expenditure

Vector $\mathrm{z}=$ measures input use intensity and serves to form a frontier by connecting linearly 'best -practice' farms.

The objective function (4) expresses the optimal return to inputs.

The first set of constraints (5) show the maximum possible output of the farmers.

The second set of constraints (6) expresses the minimum possible variable inputs that can be used. The third set constraint (7) shows the level of fixed inputs that a farmer who is a best performer should not exceed.

The last constraint (i.e., summing $Z$ to one) allows the technology to have increasing, constant, and decreasing returns to scale (Whittaker et al, 1995). Farms will be efficient if $Z$ equals one. In other word a composite unit cannot be constructed which outperforms it. If $Z$ is smaller than one, farm will be inefficient. Hollingsworth and Parkin (1998) concluded that a composite unit provides targets for the inefficient unit and $\mathrm{Z}$ represents the maximum inputs a farm should be using to attain at least its current output. This model gave the profitability coefficient rankings for each farm as compared to the 'peers'. 


\section{Results and discussions}

\subsection{Profit efficiency of smallholder pig farmers}

DEA model was used to calculate profit efficiency levels of smallholder pig farms that is efficiency rankings of the farms. DEA model was run with factors of production and marketing costs as inputs and the farm profits as the output to give us the profit efficiency rankings of the farms.

The results of DEA software revealed that the average efficiency to be $40 \%$ (table 1). Showing that, most farmers had low ranking when compared to each other. Relative efficiency ranges between zero and one $(0 \leq \theta \leq 1)$. Optimal efficient is one, while their input and output slacks equals zero (Cooper et al., 2006).

\section{Table 1: Smallholder pig farms profit efficiency levels (P.E)}

\begin{tabular}{|c|c|c|c|}
\hline Farm P.E & $23 \quad 0.529$ & $46 \quad 0.253$ & $\begin{array}{ll}69 & 0.380\end{array}$ \\
\hline 10.597 & $24 \quad 0.278$ & $47 \quad 0.545$ & $\begin{array}{ll}70 & 0.377\end{array}$ \\
\hline 20.593 & $25 \quad 0.186$ & $48 \quad 1.000$ & $\begin{array}{ll}71 & 0.549\end{array}$ \\
\hline 30.121 & $26 \quad 0.247$ & $49 \quad 0.372$ & $\begin{array}{ll}72 & 0.692\end{array}$ \\
\hline $4 \quad 0.440$ & $27 \quad 0.840$ & $\begin{array}{ll}50 & 0.431\end{array}$ & $\begin{array}{ll}73 & 0.290\end{array}$ \\
\hline $\begin{array}{ll}5 & 0.413\end{array}$ & $28 \quad 0.253$ & $\begin{array}{ll}51 & 0.207\end{array}$ & $\begin{array}{ll}74 & 0.499\end{array}$ \\
\hline $6 \quad 0.601$ & $29 \quad 0.398$ & $52 \quad 1.000$ & $75 \quad 0.111$ \\
\hline $7 \quad 0.538$ & $\begin{array}{ll}30 & 0.789\end{array}$ & $53 \quad 0.115$ & $76 \quad 1.000$ \\
\hline $\begin{array}{ll}8 & 0.028\end{array}$ & $31 \quad 0.130$ & $\begin{array}{ll}54 & 0.133\end{array}$ & $\begin{array}{ll}77 & 0.397\end{array}$ \\
\hline $9 \quad 0.792$ & $32 \quad 0.552$ & $\begin{array}{ll}55 & 0.141\end{array}$ & $\begin{array}{ll}78 & 0.596\end{array}$ \\
\hline $\begin{array}{ll}10 & 0.899\end{array}$ & $33 \quad 0.096$ & $\begin{array}{ll}56 & 0.300\end{array}$ & $\begin{array}{ll}79 & 0.949\end{array}$ \\
\hline 110.524 & $34 \quad 0.392$ & $\begin{array}{ll}57 & 0.279\end{array}$ & $80 \quad 0.521$ \\
\hline $12 \quad 0.344$ & $35 \quad 0.205$ & $58 \quad 0.420$ & \\
\hline $13 \quad 0.193$ & $36 \quad 0.100$ & $\begin{array}{ll}59 & 0.187\end{array}$ & Mean 0.402 \\
\hline $14 \quad 0.323$ & $\begin{array}{ll}37 & 0.101\end{array}$ & $60 \quad 1.000$ & \\
\hline $15 \quad 0.382$ & $38 \quad 0.876$ & $61 \quad 0.500$ & \\
\hline 161.000 & $39 \quad 0.151$ & $\begin{array}{ll}62 & 0.387\end{array}$ & \\
\hline $17 \quad 0.395$ & $40 \quad 0.232$ & $\begin{array}{ll}63 & 0.189\end{array}$ & \\
\hline $18 \quad 0.094$ & $41 \quad 0.127$ & $\begin{array}{ll}64 & 0.373\end{array}$ & \\
\hline $19 \quad 0.301$ & $42 \quad 0.399$ & $\begin{array}{ll}65 & 0.302\end{array}$ & \\
\hline $20 \quad 0.167$ & $43 \quad 0.138$ & $\begin{array}{ll}66 & 0.541\end{array}$ & \\
\hline $21 \quad 0.385$ & $44 \quad 0.108$ & $\begin{array}{ll}67 & 0.117\end{array}$ & \\
\hline $22 \quad 0.307$ & $\begin{array}{ll}45 & 0.172\end{array}$ & $\begin{array}{ll}68 & 0.267\end{array}$ & \\
\hline
\end{tabular}

Five farms had profit efficiency score of 1 thus they were efficient while the rest were inefficient from the table 1 . The most inefficient farm had inefficiency level of 0.005 , thus had to reduce input costs by $99.5 \%$ in order to acquire its target value. Target value refers to the value that is generated as target which would take the farm to the efficient level. Therefore, farmers had a chance of increasing profitability by $60 \%$ through reducing input excesses so as to reduce their costs. Farmers therefore need to reduce the amount of inputs quantities used while maintaining their output (Coelli, 1996). This shows that pig farmers still haven't reached optimal level of profitability.

The DEA method of analyzing this data was input orientated. The results showed how the farms would proportionally reduce the quantity of inputs used without changing the output produced to ensure the farms become profit efficient. Input slacks/ excess after analysis showed the amount of input quantity that can be reduced and still obtain the same level of output as before as the farm efficiency level moves up the rank.

Table 2: Input slack results

\begin{tabular}{l|l}
\hline Input slacks & Average slacks per farm \\
\hline Feed costs & 461 \\
Contacting costs & 355 \\
Contracting costs & 323 \\
Labour costs & 4824 \\
Veterinary and drugs costs & 79 \\
\hline Average input slacks & $\mathbf{1 2 0 8}$ \\
\hline
\end{tabular}

The average input slack value was found to be Kshs 1208 for each farm in table (2). The results reveal that each smallholder pig farmer had a chance of reducing input costs by this amount per year without compromising their profit levels. This would make them to move up the profit efficiency ranks.

Feed costs was found to be the highest cost a farmer incurred but with a slack value of 461 . Labor slack value was the highest amounting to 4824. It means that the farmers have a chance of reducing costs of this amount per year on labor wages and still produce the same quantity of output. Search and contracting costs had slack values 
of 355 and 323 respectively. Lastly, drugs and veterinary costs had a slack value of 79 .

\section{Conclusion}

The DEA results determined efficient and inefficient pig farms with respect to five variable costs (Feed, labor, search, contract and drugs/veterinary). This technique helped to determine which farms had the best practices and also provided helpful insights for farm management. This concurs with the findings of Hiedari et al., (2011) where the DEA helped them to segregate efficient from inefficient farmers.

The DEA results showed that farms' efficiency level averaged $40 \%$ indicating that the farms can potentially increase their profits by $60 \%$, by reallocating inputs. This means that the total input cost could be reduced by $60 \%$ without reducing the income from its present level (Hiedari et al, 2011). This is consistent with the findings of Kadurumba et al., (2014) who concluded that the prices of pig farming inputs and marketing costs can have a major influence in pig farming profitability. According to Hiedari et al (2011) an efficiency score of a farmer less than one indicates that he is using more input than required and therefore it will be helpful to avert wastage of input without reducing the output level.

The profit efficiency and its influencing factors across the study areas are expected to influence policies on industry inputs, marketing issues and financial products. Once favourable policies are recommended the outcome is expected to have a feedback effect on improving profit efficiency and profitability.

Eventually, enhanced incomes, livelihoods and welfare are anticipated. Improved profitability among the smallholder pig farmers are expected to have a feedback effect on management and institutional arrangements factors through informed and improved use of inputs, accessibility of efficient institutional arrangements and alteration of the current management aspects of the farmers.

\section{Recommendations}

Ministry of Livestock Development (MoLD) and Non-governmental Organizations (NGOs) should come up with plans and strategies which will help improve productivity through benchmarking. The best practice of bestperformers (efficient farms) should be adopted by poor-performers (inefficient farms) in-order to enhance their performance.

All stakeholders of pig sub sector should be encouraged to contribute towards formulation of policies pertaining to pig enterprise inputs, marketing issues and financial products in order to improve pig farmers' livelihoods.

\section{References}

Charnes, A.,Cooper, W.W.,Lewin,A.Y., \& Seiford,L.M. 1994. Data Envelopment Analysis: Theory, Methodology and Applications: Boston: Kluwer Academic Publishers.

Coelli, T.J. 1995. Recent Development in Frontier Modeling and Efficiency Measurement. Australian Journal of Agricultural Economics. P (219-245)

Coelli,T. 1996. A guide to DEAP version 2.1: A data envelopment analysis (Computer) program. CEPA working paper.

Cooper,W.W., Seiford, L.M. \& Tone.2006. Introduction to Data Envelopment Analysis and its Uses: with DEA Solver software and references: Newyork: Springer.

Costales,A., Delgado,C., Catelo,M.A., Tiangco,M., Ehiu,S \& Bautista. A. 2006. Scale Access Issues Affecting Smallholder Hog Producers In An Expanding Peri-Urban Market: Southern Luzon, Philippines. Research Report. ILRI

FAO. 2012. Pig Sector Kenya. FAO Animal production and Health Livestock Country reviews. No. 3. Rome.

G.O.K. 2009. Economic Indicator Survey. Nairobi. Kenya National Bureau of Statistics.

GOK. 2013. County Integrated Development plan Tharaka Nithi County. Government of Kenya, Nairobi.

Hiedari, M.D, Omid, M, Akram. A. 2011. Using non-parametric analysis (DEA) for measuring technical efficiency in Poultry farms. Brazilian journal of Poultry Science. Vol.13. n. 4. p(271-277)

Hollingsworth, B.\& Parkin D. 1998. Developing efficiency measures for use in the NHS, A report to the NHS Executive Northern and Yorkshire R \& D Directorate, Health Economics Group, University of New castle.

Jacobs, R. 2000. Alternative Methods to Examine Hospital Efficiency: Data Envelopment Analysis and Stochastic Frontier Analysis. Discussion Paper 117. University of York, Center for Health Economics

Jaetzold, R\& Schmidt, H. 1983. Farm Management Handbook: Natural and Farm Management Information Vol.11/B. Nairobi: Ministry of Agriculture and Livestock Development and GTZ.

Kadurumba, C., Kadurumba, O. E \& Ahiwe, E. U. 2014. Measurement and Sources of Economic Efficiency in Pig Production in Ebonyi State Nigeria: A stochastic Frontier Function Approach. Journal of Science Education Development Institute 4 (2)1522-1527.

Kagira, J. M, Maingi N, Kanyari, P.W.N, Githigia, S.M, Ng'ang'a, J.C \& Gachohi, J.M .2010. Characteristics of pig trade in low income settings in Busia District, Kenya. Tanzania Vet. J., 27(1): 27-35 
Key,N., Sadoulet,E \& de Janvry,A. 2000. Transaction costs and agricultural household supply response. American Journal of Agricultural Economics. 82: 245-259.

KIT, Faida Mali \& IIRR. 2006. Chain Empowerment: Supporting African Farmers to Develop Markets. Amsterdam; Arusha; and Nairobi. English Press Ltd.

Kothari, C. R .2005. Research Methodology: Methods and Techniques. New Age International (P) Limited, Publishers. New Delhi.

Levy, M.A., Dewey, C.E., Poljak ,Z., Weersink ,A \&Mutua, F.K. 2014.Pig marketing and factors associated with prices and margins in Western Kenya. Journal of Agricultural Economics and Development Vol. 2(10), pp. 371-383

Mutua, F.K., Arimi, S., Ogora, W.,Dewey, C., Schelling, E. 2010. Farmer perceptions on Indigenous pig farming in Kakamega District, Western Kenya. Nordic Journal of African Studies. P (43-57).

Whittaker, G., Biing-Hwan, L and Utpal v.1995. Restricting Pesticide Use: the impact on Profitability by Farm Size, Journal of agriculture and applied Econ.27 (2):1995:352-362 